\title{
Programa de mentoria online: espaço para o desenvolvimento profissional de professoras iniciantes e experientes*
}

\author{
Aline Maria de Medeiros Rodrigues Reali \\ Regina Maria Simões Puccinelli Tancredi \\ Universidade Federal São Carlos \\ Maria da Graça Nicoletti Mizukami \\ Universidade Mackenzie
}

\section{Correspondência: \\ Regina Maria S. P. Tancredi \\ Rua das Primaveras, 59 \\ 13566-510 - São Carlos - SP \\ e-mail: drpt@ power.ufscar.br}

*Agradecemos à FAPESP e ao CNPq que financiam o projeto e possibilitam o desenvolvimento da pesquisa.

\section{Resumo}

Apresentam-se, nesse texto, os referenciais teórico-metodológicos e resultados iniciais de uma pesquisa-intervenção sobre processos formativos de mentoras e de professoras iniciantes. A formação das iniciantes pelas mentoras ocorre no Programa de Mentoria do Portal dos Professores da UFSCar (www. portaldosprofessores.ufscar.br) e a formação das mentoras (professoras experientes) em reuniões presenciais com as pesquisadoras, autoras desse trabalho. A pesquisa e a intervenção têm como base uma metodologia construtivocolaborativa e as principais ferramentas de coleta de dados são as narrativas - escritas e orais - e conversas interativas. Relativamente ao referencial teórico, compreende-se: a aprendizagem da docência como processo contínuo no qual influem crenças, concepções, além de conhecimentos de diferentes naturezas; a iniciação à docência como período conflituoso e ao mesmo tempo rico, de aprendizagens intensas, durante 0 qual o professor iniciante se torna ef etivamente professor; que formadores de professores assim como professores em geral - precisam de apoio para o seu desenvolvimento profissional; que a formação continuada deve ser centrada na escola, mesmo quando virtualmente, e focalizar o atendimento das demandas indicadas por professores considerando o contexto de atuação; que a educação online via internet é uma possibilidade importante para a formação de professores. Entre os resultados obtidos, destacam-se: a construção de novos conhecimentos profissionais pelas professoras iniciantes, mentoras e pesquisadoras; a vivência, pelas mentoras - professoras experientes e bem sucedidas -, de processos de iniciação semelhantes aos das professoras iniciantes que orientam; as potencialidades de comunidades de aprendizagem e das narrativas para a promoção do desenvolvimento profissional da docência.

\section{Palavras-chave}

Formação de professores iniciantes - Formação de formadores Programa de mentoria - Educação online. 


\title{
Online mentorship program: a space for the professional development of beginner and experienced teachers*
}

\author{
Aline Maria de Medeiros Rodrigues Reali \\ Regina Maria Simões Puccinelli Tancredi \\ Universidade Federal São Carlos \\ Maria da Graça Nicoletti Mizukami \\ Universidade Mackenzie
}

Contact:

Regina Maria S. P. Tancredi

Rua das Primaveras, 59

13566-510 - São Carlos - SP

e-mail: drpt@ power.ufscar.br

'The authors wish to acknowledge the support given by FAPESP and CNPq to the development of this research.

\begin{abstract}
The text introduces the theoretical-methodological framework, and initial results, of an intervention-research about the formative processes of beginner teachers and their mentors. The initial formation of teachers by their mentors takes place under the Mentorship Program of the UFSCar Teachers' Portal (www.portaldosprofessores.ufscar.br), and the formation of mentors (experienced teachers) happens in presence meetings with the authors of this work. Research and intervention are based on a constructive-collaborative methodology, and the main tools of data-gathering are the narratives - both written and spoken - and interactive conversations. The theoretical framework assumes that: the learning of teaching is a continuous process influenced by beliefs and conceptions, and by knowledges of different natures; the initiation to teaching is a conflicting, but rich, period of intensive learning, during which the beginner teacher effectively becomes a teacher; teacher educators - just as teachers in general need support for their professional development; continued education must be school-centered, even when virtually, and focus on responding to teachers' demands considering the context of the action; online education via the Internet is an important possibility for teacher education. Among the results, we mention the construction of new professional knowledges by the beginner teachers, mentors, and researchers; the experience by the mentors - seasoned and successful teachers - of initiation processes similar to those undergone by the beginner teachers they supervise; the potentials of learning communities and of narratives for the promotion of the professional development of teaching.
\end{abstract}

\section{Keyw ords}

Initial teacher education - Mentor formation - Mentorship program - Online education. 
A despeito dos inúmeros investimentos voltados para a Educação Básica nos últimos anos, observamos que a qualidade do ensino recebido pela população brasileira, mesmo em centros urbanos desenvolvidos, tem deixado a desejar. Inúmeros indicadores educacionais podem ser apontados como reveladores dessa situação que se prolonga no tempo (Klein, 2003).

Embora 0 acesso e a permanência dos alunos na escola sejam realidade, freqüentemente inúmeros estudantes concluem o Ensino Fundamental sem terem pleno domínio da língua materna e de outros conteúdos escolares considerados elementares e indispensáveis para a vida no mundo atual. Mesmo um aluno aprovado pode ser considerado fracassado "porque se acomodou, porque não pensa a partir de elaborações próprias, não se autoriza a falar o próprio pensamento, porque não consegue escrever, apenas registra e copia o pensamento dos outros" (Dani; Isaía, 1997, p. 1). Segundo essas autoras, o fracasso também se apresenta "no aluno que triunfa, vence na escola e é tido como 'bom aluno' porque repete o que o professor quer e diz".

0 fenômeno do fracasso escolar, mesmo com novas vestimentas, compõe uma problemática complexa, multifacetada e multideterminada. Não se pode negar, no entanto, que dentre as suas inúmeras causas, a formação de professores possa ser destacada. Embora a literatura não aponte de forma conclusiva a influência da qualificação dos professores sobre o desempenho dos alunos, acreditamos fortemente na relação entre uma boa formação profissional e uma atuação competente.

Compreende-se, hoje em dia, que ensinar relaciona-se com o entendimento do outro, dos estudantes, da matéria, da pedagogia, do desenvolvimento do currículo, das estratégias e técnicas associadas com a facilitação da aprendizagem para o aluno, entre outros aspectos. Ser professor envolve esses aspectos do ensinar, mas também o desempenho de outros papéis e responsabilidades no âmbito da instituição escolar e de outras comunidades profissionais (Knowles; Cole; Presswood, 1994), caracterizando uma atividade profissional complexa.
Entre as características da docência, está a de que aprender a ensinar e a ser professor são processos contínuos que ocorrem ao longo da vida, o que leva a considerar que a competência profissional para a docência não é conseqüência apenas da realização de cursos de formação inicial ainda que em nível superior. Em virtude disso e também da mutabilidade do mundo moderno, é imprescindível o oferecimento de apoio para que esses profissionais possam continuar a aprender durante a carreira, desenvolvendo-se profissionalmente.

Com relação à carreira docente, a literatura da área de formação de professores vem destacando a existência de diferentes fases, com características e problemáticas próprias, 0 que nos leva a considerar que futuros professores, professores iniciantes e aqueles mais experientes apresentam competências profissionais distintas e demandas de formação específicas. Entretanto, ao levarmos em conta a realidade brasileira, as escolas exigem dos professores iniciantes desempenhos semelhantes aos experientes e os programas de formação continuada não têm dado ênfase às especificidades das fases da carreira, desenvolvendo propostas generalizantes, mesmo quando centradas na escola.

0 presente artigo aborda essa problemática a partir dos resultados iniciais de um projeto de pesquisa e intervenção que objetiva, por meio da adoção de uma abordagem construtivo-colaborativa, avaliar as contribuições de um Programa de Mentoria, via WEB, para o desenvolvimento profissional de professoras iniciantes e de professoras experientes - as mentoras -, que dão suporte às primeiras em suas dificuldades profissionais. Trata-se do Programa de Mentoria do Portal dos Professores da UFSCar, desenvolvido sob a responsabilidade das autoras.

\section{A pesquisa em parceria e a construção do conhecimento educ acional}

Nas últimas décadas, a pesquisa sobre o ensino e sobre os processos de escolarização 
passou por um período de mudanças conceituais e metodológicas. Cada vez mais, os professores e as práticas pedagógicas têm sido investigados a partir de perspectivas que visam favorecer a compreensão da complexidade dos processos envolvidos na vida da escola e as características singulares de seus participantes.

Ao estudar os fenômenos ocorrentes nas escolas, nas salas de aula e o trabalho de professores, os pesquisadores penetram nas salas de aula e nas escolas para observar, participar e discutir o ensino e a aprendizagem com os seus principais protagonistas: os professores e os alunos. Quando desenvolvem pesquisas que associam intervenções com vistas à melhoria dos processos desenvolvidos, freqüentemente partem das necessidades identificadas pelos próprios professores ou por outros membros da comunidade escolar. Tais investigações caracterizam-se por uma inserção mais prolongada, na escola, dos chamados parceiros da universidade.

0 modelo de pesquisa e intervenção implica, nesses casos, conhecer a realidade em que os professores atuam, o que pensam, o que fazem e porque o fazem para, colaborativamente, refletir com eles sobre as situações vivenciadas e, caso necessário, construir formas de enfrentamento das dificuldades que considerem as especificidades das escolas e da comunidade. A forma colaborativa de interação entre os pesquisadores e os professores enfatiza a importância do estabelecimento de propósitos e interpretações múltiplas. 0 sentido construtivo é dado pelo pressuposto de que o ensino está em permanente desenvolvimento. Nessa perspectiva, as situações consideradas dilemáticas ou problemáticas exigem a tomada de decisões e a construção de soluções coletivas (Cole; Knowles, 1993).

Segundo essa perspectiva, há necessidade de se estabelecer com as escolas um trabaIho processual, que se defina como uma via de mão dupla, evitando encará-las apenas como fornecedoras de dados para a atividade de pesquisa. Em linhas gerais, isso significa conceber que as partes envolvidas assumem papéis de natureza colaborativa, diferentes sim, mas em que cada um tem o que aprender com 0 outro e em que a relação estabelecida entre os professores da escola e os da universidade é multifacetada e não hierarquizada.

Esses modelos de pesquisa se pautam num referencial denominado construtivo-colaborativo, cujas idéias principais foram sistematizadas por Mizukami et al. (2002).

Com relação à aprendizagem da docência, Cole e Knowles (1993) vêm nos ensinando que é um processo contínuo que começa antes da preparação formal nos cursos específicos, prossegue ao longo deste e permeia toda a prática profissional. Essa aprendizagem é influenciada por diferentes fatores, entre os quais destacamos os cognitivos, os afetivos, os éticos, de desempenho, as crenças e os valores que têm os professores e o contexto em que atuam.

Por ser desenvolvimental, a aprendizagem da docência requer tempo e recursos para que novas concepções, novos valores, novas técnicas sejam confrontadas com as que os professores já têm e comprovem sua eficácia na situação de atuação. Não basta, para mudar a prática, aprender novas vertentes teóricas ou novas técnicas. Quando um professor deseja ou precisa fazer mudanças e desenvolver novas práticas para contemplar exigências sociais ou políticas públicas, ele precisa fazer revisões conceituais, entre elas, aquelas sobre o processo educacional e instrucional e sobre os suportes teóricos da própria atuação.

Um outro aspecto deve ser considerado: o ensino é um ato dinâmico, não completamente previsível, sujeito ao que acontece na classe, na interação com os alunos e também no contexto institucional. A essas situações, 0 professor precisa dar uma resposta e faz isso em função do constante monitoramento do que ocorre durante a aula, agindo com base em percepções e interpretações sobre o que está acontecendo (Schoenfeld, 1997).

Conhecimentos, crenças, metas e hipóteses dos professores, suas concepções sobre a matéria que lecionam, o conteúdo curricular, os 
alunos e a aprendizagem são, portanto, elementos fundamentais na determinação do que eles fazem em sala de aula e do porquê o fazem.

Para agirem nas situações instáveis e complexas da sala de aula, os professores precisam de uma base de conhecimento, composta por conhecimentos de diferentes tipos e natureza, os quais sustentam seus processos de tomada de decisões. Essa base de conhecimento é constituída por um conjunto de compreensões, conhecimentos, habilidades e disposições necessárias para atuação efetiva em situações específicas de ensino e aprendizagem (Shulman, 1986; 1987).

Os conteúdos dos conhecimentos profissionais dos professores - conhecimento pessoal prático, da profissão, de casos, dos fundamentos educacionais, de metáforas, dentre outros - são igualmente importantes para 0 processo de desenvolvimento profissional da docência (Schoenfeld, 1997).

Consideramos que a aprendizagem da docência ocorre como exposto e advogamos que os programas de formação continuada devem estar adaptados às necessidades próprias dos professores, a escolas específicas, considerando que a aprendizagem do adulto se volta mais diretamente ao prático que ao teórico (Darling-Hammond, 1994; Marcelo Garcia, 1998; Calderhead, 1996; Schoenfeld, 1997). Tais ações deveriam dar respostas para os problemas enfrentados pelos professores no dia-adia. Dessa forma, sua estrutura e o conteúdo deveriam ser determinados, substancialmente, pelos professores.

Uma das estratégias formativas que pensamos ser adequada para a formação continuada de professores e que atende às especificidades apontadas é a reflexão sobre a ação pedagógica, que deve ocorrer no local de trabalho, com os pares, embora não deva se limitar a ele.

A reflexão é vista por nós, com base em Hatton e Smith (1995), como um processo cognitivo ativo e deliberado que envolve seqüências de idéias inter-relacionadas que levam em consideração experiências, crenças e conhecimentos tácitos e teóricos. É geralmente endereçada para a solução de problemas práticos e envolve a dúvida e a perplexidade. Esse processo reflexivo, que se sustenta no conceito introduzido por Dewey, deve ocorrer em comunidade, em interação com os outros e, segundo Rodgers (2006), abrange quatro fases: a experiência, a descrição, a análise e a ação inteligente.

Para favorecer processos reflexivos, as escolas, por meio de políticas públicas, deveriam assegurar tempo e espaço mental para os professores se desenvolverem profissionalmente no local de trabalho (McDiarmid, 1995). Nesse espaço, seria possível favorecer o desenvolvimento profissional de todos aqueles que, de uma forma ou de outra, participam do processo educativo (professores, corpo técnico-administrativo, alunos, famílias, comunidade). Centrar a formação continuada na escola poderia, assim, reverter em benefícios para a escola e para os processos de ensino e de aprendizagem nela realizados.

Aberta essa possibilidade, o sistema ou instituição educacional poderia se perceber como uma organização que aprende, que se desenvolve pela aprendizagem de seus membros e que, ao adotar uma dinâmica formativa contínua e compartilhada, acompanha e propicia mudanças na realidade em função das suas necessidades e de seus objetivos (Argyris; Schön, 1996).

Embora consideremos que, prioritariamente, a formação continuada deve centrar-se na escola e nas necessidades dos seus professores, esse centrar-se não precisa referir-se apenas ao espaço físico. Mais importante que isso, é centrar-se nas necessidades dos professores, essas sim contextualizadas em seu local de trabalho. Dessa forma, a formação pode ocorrer em outras instâncias (físicas) e mesmo a distância, sem que a escola deixe de ser um elemento fundamental. Ela apenas passa a estar presente por intermédio de seus professores, o que é da maior relevância. Nada adianta usar fisicamente o espaço escolar e oferecer aos professores progra- 
mas fechados de formação, que não considerem 0 enfren-tamento das situações vividas e que precisam ser superadas.

Nessa vertente que propomos, a colaboração entre os participantes da atividade formativa é fundamental, sendo concebida como diálogo, implicando pessoas engajadas em conversações, trocas e desenvolvimento profissional recíproco. Esse tipo de colaboração permite compreensões mútuas e consenso, tomada de decisão democrática e ação comum (Clark et al., 1996; 1998); implica uma tendência para a inquirição, que objetiva gerar novos conhecimentos e contemplar problemas do dia-a-dia escolar.

A apresentação das necessidades, a reflexão sobre a realidade, a sua interpretação considerando 0 contexto ao qual se referem e uma base teórica sobre o fenômeno analisado é também um ato colaborativo (Wasser; Bresler, 1996), no qual

\section{[...] múltiplos pontos de vista são considera-} dos em tensão dinâmica quando um grupo procura dar sentido a temas/problemas e significados de um campo de trabalho. (p. 5)

No caso do projeto em tela nesse artigo, cujo caráter é de pesquisa-intervenção, as idéias apontadas anteriormente são básicas e se justificam principalmente por dois aspectos: um relativo à característica processual e colaborativa de pesquisas que envolvem professores; outro, à natureza do programa formativo proposto, que objetiva promover aprendizagens profissionais de professores em diferentes fases da carreira e fomentar o seu profissionalismo ao mesmo tempo em que permite a construção de conhecimentos sobre os processos envolvidos.

No caso desse último aspecto, estão sendo considerados: o cenário atual das reformas educativas e o papel da educação a distância nesse contexto; a limitação de muitos dos processos vigentes de formação inicial e continuada; a necessidade premente de que os professores (de diferentes níveis e modalidades de ensino) desenvolvam uma base de conheci- mento sólida e compatível com as demandas da sociedade em relação à escola.

\section{De professor iniciante a}

experiente: conhecendo alguns

elementos/facetas da aprendizagem da docência

Embora a área de formação de professores seja relativamente recente, nos últimos 20 anos, temos tido evidências de que o desenvolvimento profissional pode conduzir a melhorias nas práticas docentes e na aprendizagem dos alunos. No entanto, estamos ainda começando a compreender 0 que e o como os professores aprendem no processo de desenvolvimento profissional e sobre 0 impacto das mudanças dos professores na aprendizagem dos alunos.

Sabemos que a aprendizagem docente é um processo contínuo que ocorre ao longo da trajetória dos professores; que não se limita aos espaços formais e tradicionais de formação; e que os professores aprendem ensinando e aprendem com outros professores. Aprendem ainda via processos de observação vivenciados ao longo de suas vidas como estudantes. Podemos entender a aprendizagem docente como estando relacionada a diferentes fases da vida: as que antecedem a formação inicial, a formação inicial, a relativa aos primeiros anos de inserção profissional, a relacionada ao desenvolvimento profissional. Nesse sentido, as demandas formativas dos professores se alteram em função da fase da carreira e de características contextuais mais específicas.

Sabemos também que nos processos de aprendizagem profissional da docência ocupam lugar de destaque as teorias pessoais (ou crenças, valores, juízos, opiniões, concepções) dos professores que, de certa maneira, definem fortemente suas práticas pedagógicas. Essas crenças são influenciadas pelas experiências pessoais, experiências com o conhecimento formal, experiências escolares e com a sala de aula. A base de conhecimento para 0 ensino e o processo de raciocínio pedagógico (Shulman, 
1986; 1987) são outros aspectos fundamentais a serem considerados nos processos de aprendizagem profissional da docência.

Aparentemente, professores em início de carreira e aqueles mais experientes apresentam diferenças na base do conhecimento para 0 ensino - embora seja necessário destacar que mais experiência não se relaciona diretamente com mais anos de prática ou com melhores práticas -, competências profissionais distintas e demandas formativas específicas.

A literatura aponta que a formação inicial costuma ser um antídoto fraco para desmanchar/apagar as teorias pessoais que norteiam as práticas pedagógicas dos professores e que têm como base suas experiências passadas, especialmente como aluno (Ball; Cohen, 1999). Essas teorias funcionam como filtros para novas aprendizagens de modo que crenças culturalmente sustentadas dificilmente são confrontadas. Ao contrário, são reforçadas.

Em linhas gerais, os primeiros anos da docência compõem uma fase em que o professor aparentemente sofre um tipo de "miopia" (Grossman; Thompson; Valencia, 2001), pois focaliza suas ações em competências mais voltadas para a sua socialização na instituição escolar e no gerenciamento das demandas mais imediatas da sala de aula, como o controle da disciplina dos alunos, do que propriamente o processo de ensino e aprendizagem. Pode ser configurado, com algumas variações, como o período compreendido pelos primeiros cinco anos de exercício docente, embora outros aspectos possam ser considerados nessa classificação.

De acordo com esses autores, professores em início de carreira caracterizam-se pela energia positiva, a esperança - às vezes marcada por fantasias românticas sobre seu papel - 0 otimismo. Simultaneamente, vivenciam uma rede de desafios e demandas que têm impacto sobre suas crenças sobre como devem atuar. 0 conjunto de demandas e desafios pode minar as energias dos iniciantes e converter o otimismo em desânimo e desesperança. Este costuma ser um período caracterizado pela incerteza, dúvida e tensão - além de se configurar também como um período de aprendizagens intensas em contextos pouco conhecidos e cujas tarefas principais são a construção de conhecimentos profissionais e a manutenção de equilíbrio emocional. Muitas vezes, essa é uma fase marcadamente solitária, em que a imitação acrítica de outros professores prepondera e a transferência dos conhecimentos teóricos adquiridos anteriormente para a prática é difícil.

Como mecanismo de sobrevivência, muitos professores iniciantes priorizam as relações interpessoais em detrimento das aprendizagens dos conteúdos específicos, via acordos tácitos em que ensinam pouco, mas mantêm boas relações com os alunos (Van Zanten; Grospiron, 2001). Há ênfase nas questões práticas de sala de aula e em processos de aprendizagem baseados no ensaio-e-erro. Os professores podem assumir ainda as seguintes posturas: rejeição ou abandono dos conhecimentos acadêmicos; transposição de uma concepção teórica sem uma análise mais aprofundada dos problemas; questionamento da prática pedagógica e da cultura escolar. 0 ajuste a normas, valores, propósitos e limitações institucionais; a submissão estratégica aos valores e concepções da instituição escolar ou o não questionamento e a tentativa de mudança da situação com que não concorda seriam outras atitudes típicas das primeiras fases da carreira docente. Aparentemente as primeiras experiências marcam definitivamente os processos de socialização e desenvolvimento profissionais.

Mesmo considerando a força das experiências vividas, os professores experientes parecem pautar suas ações em estruturas diferentes e mais complexas que os iniciantes; parecem exercer um controle voluntário e estratégico sobre o processo ensino-aprendizagem, que ocorre de modo mais automatizado no caso dos iniciantes (Pacheco; Flores, 1999).

Os professores experientes possivelmente detêm uma quantidade maior de conhecimentos de diferentes naturezas, o que favorece um quadro de referências mais amplo para lidar com as demandas do ensino. Esse quadro tam- 
bém parece ser mais complexo e menos superficial quando comparado ao de professores iniciantes. De modo semelhante, a representação dos problemas parece ser diversa no caso dos experientes, pois tendem a se ater numa estrutura abstrata do problema e utilizar como referência uma variedade de problemas armazenados na memória.

Professores experientes apresentam maiores conhecimentos sobre os alunos em termos de suas habilidades cognitivas, estilos de aprendizagem e características pessoais. A experiência favorece a construção de um conhecimento situado - que é desenvolvido em função dos contextos de atuação e é acessado e utilizado como ferramentas de solução para os problemas. São também mais responsivos às demandas dos ambientes e capazes de alterar o rumo de suas ações em resposta às necessidades dos alunos e às variáveis do ambiente. Detêm um tipo de estoque de informações que são usadas como lentes para interpretar os eventos, construindo, portanto, representações mais complexas sobre o ensino.

Por esses motivos são capazes de desenvolver oportunidades mais efetivas de aprendizagem com grupos de alunos específicos.

Entretanto, independente da fase da carreira, os professores constroem conhecimentos profissionais a partir da interação de suas experiências anteriores com as atuais, e os processos envolvidos são situados, envolvem interação social e são distribuídos com outros, porque ninguém dispõe da totalidade dos conhecimentos e das habilidades para o ensino de forma individual. A partir desses aspectos todos, questionamos: o que levar em consideração para o desenvolvimento de programas formativos voltados para a melhoria da atuação docente?

Para Borko (2004), os professores devem aprender como aprender com a prática, uma vez que o ensino requer improvisação, conjecturas, experimentação. Para isso, parece ser necessário que os professores:

1. aprendam a adequar seus conhecimentos a cada situação, o que implica indagar sobre 0 que os alunos fazem, pensam e como compreendem o que é ensinado;

2. acompanhem, guiem e revisem as tarefas dos alunos;

3. aprendam a utilizar seu conhecimento para melhorar a sua prática;

4. apresentem disponibilidade mental para a mudança;

5. tenham oportunidades de vivenciar situações em que tais processos ocorram.

As aprendizagens centradas nas práticas não necessitam ser em tempo real: os professores podem utilizar materiais instrucionais voltados para a aprendizagem e 0 desenvolvimento da docência, como casos escritos e multimídias, observações de situações de ensino e exemplos de tarefas de alunos. Os materiais devem permitir que os professores indaguem sobre práticas e analisem o próprio ensino ou o de outros professores.

Considerando os programas de aprendizagem profissional da docência, outros aspectos podem ser destacados.

De acordo com Borko (2004), no que se referem ao plano individual, os programas devem enfatizar o conhecimento da matéria, a compreensão sobre o pensamento dos alunos e as práticas instrucionais.

Para promover a compreensão dos conteúdos escolares, os professores devem conhecer o conteúdo que ensinam; compreender os fatos centrais e os conceitos fundamentais da matéria e como essas idéias estão relacionadas entre si; e também saber os processos adotados para a construção de novos conhecimentos na área de conhecimento. Programas formativos que focalizam os conteúdos específicos podem auxiliar os professores a desenvolver repertórios adequados, em especial se envolverem os professores em experiências voltadas para solução de problemas.

Para orientar a aprendizagem dos alunos, os professores devem compreender como as concepções dos alunos se desenvolvem e as relações que estabelecem entre as suas idéias e as da área ensinada. Por exemplo, por meio de 
diálogos mantidos em entrevistas do tipo clínico com seus alunos, os professores podem aprender sobre eles, mapear a adequação ou não das concepções apresentadas e explorar os seus pensamentos para planejar estratégias instrucionais mais pertinentes.

Ao focalizar as práticas instrucionais, os programas formativos possibilitam a discussão sobre as estratégias adotadas para solucionar os problemas, a compreensão do pensamento dos alunos, o uso das respostas destes para avaliar o seu entendimento, entre outras vantagens.

No plano dos contextos coletivos (uma escola, um grupo de professores), a pesquisa tem indicado que comunidades profissionais fortes podem promover a aprendizagem profissional e a melhoria das práticas instrucionais. A construção de uma comunidade de aprendizagem de professores (ou comunidade de prática) - compreendida como uma comunidade de profissionais que, ao interagirem, modificam ou aprendem novas ações e transformam suas identidades profissionais - tem um peso substancial na responsividade de professores às demandas originadas pelas políticas educacionais, no seu engajamento na construção de condições de ensino mais adequadas para seus alunos e, conseqüentemente, nas mudanças evidenciadas em suas práticas docentes (Mizukami et al., 2003).

Destacamos que uma comunidade de aprendizagem difere de um mero grupo de pessoas trabalhando em torno de um objetivo comum. Um dos seus aspectos distintivos diz respeito ao fato de a primeira implicar a negociação do significado do trabalho realizado por meio das aprendizagens e a identificação de um membro com os demais. De acordo com Gallucci (2003), as comunidades de prática "criam, expandem e trocam conhecimentos sobre suas práticas, assim como desenvolvem suas capacidades individuais" (p. 15).

Alguns elementos parecem chaves para a formação de uma comunidade voltada para a aprendizagem docente (Grossman; Wineburg; Woolworth, 2000): desenvolvimento de uma identidade grupal e de normas de interação; estabelecimento de um sentimento de respon- sabilidade coletiva para regulação das normas e das condutas; responsabilidade de cada membro com o crescimento e desenvolvimento dos demais membros do grupo, o que pode fomentar a aprendizagem docente. A pesquisa também tem apontado que dificilmente os professores vão engajar seus alunos em comunidades de aprendizagem se eles mesmos não pertencerem a uma que promova o seu crescimento profissional. Há evidências de que o desenvolvimento de comunidades de professores envolve processos complexos - especialmente se implicam o apoio para a análise crítica do ensino - além de demandarem tempo para ser estabelecidas (Borko, 2004).

A investigação sobre a participação de professores em comunidades de desenvolvimento profissional, ainda segundo Borko (2004), revela que os registros das práticas constituem ferramentas poderosas para facilitar mudanças nos professores, configurando-se como um novo contexto formativo. Os registros sobre a prática - escritos ou em vídeo - permitem que os professores examinem as estratégias adotadas e discutam formas de melhorá-las. Nessa mesma linha, é relevante considerar novamente que as experiências de sala de aula são fontes poderosas de aprendizagem, o que não significa que as aprendizagens profissionais devam se esgotar nelas.

\section{Programas de mentoria como a uxílio a professores iniciantes e professores experientes}

Entre as alternativas de apoio que podem ser oferecidas aos professores iniciantes, encontrase 0 trabalho de mentoria, que pode auxiliá-los a analisar a base de conhecimento profissional e a buscar meios adequados para ampliá-la, tendo em vista a aprendizagem de todos os seus alunos. Esse apoio se mostra mais importante quando consideramos que os professores atuam num mundo dominado pela mudança, incerteza e complexidade crescentes, cujas situações e problemas não são solucionáveis com a simples 
aplicação de conhecimentos técnico-teóricos disponíveis. Tais situações exigem desse profissional a tomada constante de decisões e a construção de soluções - processos em que devem "selecionar alguns aspectos, organizálos e, a partir de uma avaliação, dar-Ihes coerência e estabelecer uma direção para a sua ação" (Schön, 1987, p. 4).

Programas de indução ou de acompanhamento do professor iniciante por profissionais mais experientes nas primeiras etapas de sua carreira são poucos no Brasil. Quando um profissional em início de carreira recebe algum tipo de apoio em suas dificuldades, esta é geralmente uma iniciativa voluntária de um colega mais experiente, sem caráter institucional.

Um exemplo de programa oficial de apoio aos professores foi o PROFA, desenvolvido pelo $M E C$ recentemente e que em alguns municípios teve como diferencial acompanhar professores em seu primeiro ano de exercício profissional, como foi o caso observado em Itirapina (SP). As professoras que desenvolveram esse trabalho de formação eram experientes e vinham se dedicando à formação de professores das séries iniciais há muitos anos. Sob o ponto de vista delas, essa experiência de formação de professores iniciantes pelo PROFA foi muito bem-sucedida e permitiu que as participantes desenvolvessem sua competência profissional (Piccolli; Ohnuma, 2002).

Um outro exemplo bem-sucedido foi 0 acompanhamento de dois professores iniciantes de Educação Física, durante o seu primeiro ano de prática profissional, por uma ex-professora de seu curso de graduação. 0 acompanhamento teve por objetivos: auxiliar os jovens professores no ingresso profissional de um modo menos traumático, oferecer apoio e orientação formativa no sentido da aprendizagem e do desenvolvimento da profissão, auxiliar na socialização com a cultura escolar. Os professores iniciantes indicaram ter vivenciado uma série de emoções e desafios pessoais e profissionais e enfrentaram dificuldades para compreender os alunos, a direção, os outros docentes, o espaço físico e os materiais para aula. Ao longo do desenvolvimento do programa de mentoria, os professores iniciantes passaram a entender melhor os alunos, a direção e os outros professores. Mais do que entendê-los, tentaram fazer com que os outros os compreendessem. Nesse processo de compreender e se fazer compreendido, os professores iniciantes construíram inúmeras estratégias de ação, estabeleceram rotinas, fizeram acordos com os alunos, negociaram com a direção e os outros professores (Ferrreira; Reali, 2005).

Tal como ocorreu nos casos citados, a literatura vem indicando que os mentores geralmente devem ser professores experientes, veteranos nas experiências cotidianas de sala de aula e dos assuntos da escola, que podem auxiliar os professores iniciantes a aprender a filosofia, os valores culturais e a estabelecer um repertório de comportamentos profissionais esperado pela comunidade escolar em que atuam. Alguns programas de indução implicam 0 encontro freqüente entre o mentor e o professor iniciante; em outros, essas situações são mais esporádicas. Aparentemente, não é tanto a freqüência dos encontros que conta, mas sim a qualidade da interação estabelecida entre mentores e mentorados, conforme indicam Wang e Odell (2002) em ampla revisão sobre 0 assunto. Para esses autores, resultados de pesquisas indicam que professores iniciantes que participaram de processos de mentoria em seus anos iniciais de atuação converteram-se em professores mais efetivos e comprometidos com seus alunos, pois suas aprendizagens práticas foram orientadas em lugar de se caracterizarem pelo ensaio-e-erro.

Para Weiss e Weiss (1999), muitas experiências de indução implicam uma visão unidirecional do papel do mentor, considerado como alguém experiente que ensina alguém menos experiente. Defendemos a perspectiva que supõe o desenvolvimento de experiências mútuas, na qual profissionais com diversos graus de experiência oferecem assistência e também aprendem com a constituição de uma comunidade de aprendizagem. A primeira vertente implicitamente esta- 
belece as diferenças e as distâncias entre 0 mentor e o professor iniciante; a segunda, ao contrário, acentua as conexões entre profissionais em diferentes estágios da carreira.

Numa cultura colaborativa, professores experientes e iniciantes que trabalham conjuntamente e trocam idéias sobre problemas reais colocam sua base de conhecimento comum em ação e vivenciam relações recíprocas entre teoria e prática. Nesses casos, podem ser adotados modelos construtivistas - com ênfase na prática reflexiva e na prática colaborativa -, que podem engendrar a ampliação do repertório dos professores mentores para responder às necessidades dos professores iniciantes (Wang; Odell, 2002) e as necessidades de ensino dos professores experientes.

Consideramos que os professores iniciantes necessitam ser estimulados a examinar suas crenças sobre 0 ensino e 0 aprender a ensinar, a construir imagens de ensino coerentes com o que se preconiza como adequado e a desenvolver disposição para aprender a ensinar. Compreendemos que esses mesmos processos devem envolver a formação e atuação de mentores. Dessa maneira, a mentoria não é apenas um processo de assistência a novos profissionais na sua aprendizagem da docência, mas também uma ocasião para que os mentores continuem aprendendo e ampliem os seus processos de desenvolvimento profissional.

Acreditamos, portanto, que os efeitos positivos da mentoria podem ir além do auxílio aos professores em seu início de carreira, pois podem ser benéficos também para os mentores, no sentido de que pode se configurar num espaço para o compartilhamento de idéias e ações e para o desenvolvimento de disposições, conhecimentos e habilidades de ensinar e aprender a ensinar, que são cruciais para o apoio a professores iniciantes e para a continuidade da própria aprendizagem profissional (Wang; Odell, 2002). Com base na reflexão entre pares, os professores - iniciantes e mentores ou professores mentores entre si podem construir uma cultura colaborativa.

\section{A internet como ferramenta para a formação de professores}

A educação a distância surgiu ao final do século XIX nos EUA e na Europa com a finalidade de atender a uma população que tinha dificuldades de freqüentar cursos regulares e presenciais. Embora durante muito tempo tenha sido considerada um tipo de Educação de segunda classe, com 0 advento da informática, do crescente acesso da população aos microcomputadores e às redes de internet, dos novos processos de aquisição e divulgação do conhecimento, a educação a distância tomou novo rumo.

Dentre as diversas modalidades de educação a distância, temos a educação online, que pode favorecer 0 desenvolvimento do pensamento, a autonomia, o compartilhamento de saberes, a aprendizagem pela vida afora. Em particular, a internet tem se configurado como um amplo campo de busca: informações, documentos, textos, artigos, imagens, músicas. Permite a comunicação rápida entre as pessoas, em tempo real ou não. Possibilita, por suas características, a formação de comunidades de aprendizagens formadas por pessoas das mais diversas culturas e procedências.

Em nosso país, cada vez mais as pessoas têm acesso à internet e a tem como ferramenta essencial na vida moderna, o que torna aprender online uma prática não distante do dia-a-dia. Também as escolas, ainda que de maneira pouco satisfatória, vêm procurando incorporar o seu uso nos processos educacionais, oferecendo várias modalidades formativas, tanto em nível educacional (ensino técnico, graduação, pós-graduação, por exemplo) como em áreas do conhecimento.

Um sério problema que se observa nos cursos que ocorrem via internet é a tendência de transferir uma concepção de ensino e aprendizagem dos bancos escolares para os computadores: a transmissão do conhecimento. No nosso ponto de vista, para que a educação online possa atingir seu potencial máximo, é importan- 
te que sejam adotadas concepções e práticas de ensino e aprendizagem que considerem os envolvidos como aprendizes ativos e responsáveis pelo próprio desenvolvimento, o qual se dá ao longo da vida e em diferentes contextos, não apenas nas escolas.

Apesar dos problemas existentes, com 0 auxílio da internet, é possível construir um conjunto de atividades ajustadas às características dos alunos e das escolas, aproveitando 0 intercambio das experiências pessoais com relação a um determinado conteúdo, e isso pode desempenhar um papel relevante no desenvolvimento coletivo.

0 novo modo de aprender e de se comunicar via internet exige "um professor em novos moldes" que saiba buscar informações, "gerir as situações facilitadoras de aprendizagem, articular diferentes pontos de vista, instigar o dialogo entre os alunos e a produção conjunta, compreender a expressão do pensamento dos alunos, orientando-o em suas produções". Ele acompanha os alunos no ambiente virtual e no seu engajamento nas tarefas, analisando as estratégias adotadas e realizando intervenções voltadas para suscitar reflexões, "novos questionamentos e reconstruções do conhecimento" (Almeida, 2003, p.141).

Para Moran (2003)

[...] com a educação online os papéis do professor se multiplicam, diferenciam-se e complementam-se, exigindo uma grande capacidade de adaptação e criatividade diante de novas situações, propostas, atividades. (p. 41)

Essas mudanças no modo convencional de atuar dos professores indicam a necessidade de alterar a formação e a concepção da profissão docente. No nosso ponto de vista e considerando o contexto da internet, o que os professores precisam saber e ser capazes de ensinar deve ser ressignificado. Assim como seus alunos, os professores devem aprender a trabalhar em ambientes dinâmicos que se alteram e nos quais os conhecimentos se constroem a partir de diferentes fontes e perspectivas. Compreender 0 que e o como se aprende são demandas imprescindíveis para professores e alunos. Portanto, durante a formação, importa incluir a discussão sobre como são formados os professores, de que conhecimentos necessitam para ensinar, como aprendem a ser professor, como se organiza e consolida a profissão docente nessa sociedade do conhecimento na qual qualquer pessoa pode ter acesso às informações e pode se converter em alguém que ensina. Essas demandas também precisariam ser atendidas pela formação presencial, mas a educação online pode ocupar esse espaço formativo com propriedade por utilizar a mesma ferramenta, os mesmos recursos que se espera que os professores utilizem com seus alunos.

Não há, contudo, um padrão fundamental e um único ponto de partida para o desenvolvimento de atividades formativas voltadas para os professores com suporte em ambientes virtuais, mas para o sucesso do empreendimento, consideramos importante investir na constituição de comunidades/grupos de aprendizagens que possibilitem desencadear processos reflexivos auto-sustentados. Para isso, as abordagens adotadas para o desenvolvimento das propostas devem ser problematizadoras, e os alunos incitados a resolver os problemas apresentados.

As iniciativas em educação a distância mediadas pela internet voltadas para a formação de professores tiveram início no Brasil no final da década de 1990, com o oferecimento de uma série de cursos de extensão, especialização e graduação online. Embora recente, tem se disseminado rapidamente a cultura da formação a distância e o investimento público nesse sentido tem aumentado, especialmente nos últimos tempos, com a iniciativa do MEC de promover e financiar a Universidade Aberta do Brasil.

Embora louvável a iniciativa, alguns cuidados são importantes. Em 2003, Moran alertava para o fato de que alguns cursos online "simplificam o processo pedagógico, se preocupam pouco com a construção do conhecimento, são massificadores, só visam o lucro fácil" (p. 40) e 
continuam centrados no conteúdo, na transmissão da informação para os alunos. É a educação tradicional que prevalece na grande maioria dos cursos, como corroboram autores como Nova e Alves (2003); Ramal (2003); Santos (2003).

Outro problema, apontado por Blikstein e Zuffo (2003), é que

[...] a maioria dos projetos confia quase que exclusivamente no texto escrito como forma de interação entre pares (e-mail, listas de discussão), esquecendo-se de que ele é apenas uma das formas pelas quais as pessoas se comunicam. (p. 34-35)

Esses autores consideram que embora ainda haja dificuldades para a organização de formações mais flexíveis e que associem diferentes recursos,

[...] devemos usar o que a internet oferece de novo e positivo: a anonimidade (para jogos de aprendizado, por exemplo; Blikstein, 2001), a eliminação da distância entre pessoas que têm (ou querem ter) um vínculo de relacionamento significativo, a possibilidade de criação em expressão pessoal, a descentralização da produção de conhecimento e de sua documentação, a ausência de formatos proprietários e as possibilidades de construção coletiva de projetos reais. (p. 36)

Uma outra forma, portanto, de organizar 0 processo ensino e aprendizagem. Trata-se de adotar modelos de ensino que se baseiam em problemas, nos quais os alunos não são meros receptores de dados estáticos, mas resolvedores de problemas, os quais por sua vez são construídos em função das suas experiências e dos conhecimentos adquiridos, possibilitando o desenvolvimento de novos conhecimentos.

De modo correlato, pode-se pensar nos processos de formação docente, pois formar professores online não garante a efetividade dos resultados. Deve-se pensar em organizar os processos formativos tomando como base os problemas da prática docente, considerando os processos envolvidos na aprendizagem e no desenvolvimento profissional da docência. 0 mesmo se pode dizer quando se foca a formação de professores para atuar online. Também o professor dos professores deve estar centrado na aprendizagem dos alunos e acompanhar o desempenho nas tarefas individuais, no sentido de atender as suas necessidades e Ihes dar constante feedback.

Reconhecemos que ainda há muitas críticas sobre a possibilidade de os professores serem formados a distância, mas não podemos esquecer que também há problemas com a educação presencial tradicional, que não tem dado conta de formar os professores com conhecimentos, habilidades e atitudes que precisam para ensinar bem a todos os seus alunos. 0 mesmo podemos dizer quando o foco é a formação de professores para atuar online formando professores.

Apresentamos a seguir a proposta de formação online de professores iniciantes por professores experientes, via o Programa de Mentoria do Portal dos Professores da UFSCar, que consideramos atender os pressupostos até o momento colocados.

O Programa de Mentoria: análise preliminar de uma proposta formativa

À luz das afirmações feitas, elaboramos uma proposta formativa baseando-nos no atendimento de professores iniciantes, via internet, tendo como centro a escola, embora virtualmente, pois o seu foco são as demandas dos professores iniciantes tendo em vista o contexto de atuação, tal como percebido e relatado por eles.

No Programa de Mentoria do Portal dos Professores da UFSCar (Tancredi; Reali; Mizukami, 2005), professores com até cinco anos de carreira participam de um conjunto de atividades conduzidas sob a orientação de professores expe- 
rientes, as mentoras, profissionais socialmente reconhecidas por sua ampla e diversificada experiência em aspectos relativos às práticas de sala de aula e aqueles referentes aos processos de socialização profissional. Os principais objetivos do Programa são minimizar as dificuldades enfrentadas por professores no período de indução, isto é, nas fases iniciais de sua carreira, e formar formadores de professores presencialmente.

Considerando as características das diferentes fases da carreira docente, delineadas anteriormente, numa primeira etapa (outubro 2003 a junho de 2004), procedemos ao início do desenvolvimento profissional de um grupo de professoras experientes para 0 desempenho de atividades de mentoria, via encontros semanais e presenciais, com duas horas de duração, entre toda a equipe (professoras mentoras, pesquisadoras, auxiliares de pesquisa). Nesse período, a partir de um conjunto de atividades - estudos de casos, textos, discussões, relatos escritos e a discussão de temas comuns ao desenvolvimento e implementação do Programa de Mentoria -, definiram-se os seus modelo, as bases conceituais e as ferramentas. Nesse processo com as mentoras, consideramos suas concepções sobre ensino, aprendizagem, conhecimento, alunos, professor, escola, currículo etc., bem como o que qualificaram como necessário para desempenhar o papel de mentoras. Além disso, foram delineadas as características gerais e definidos os pressupostos, o currículo, as atividades, a duração do Programa de Mentoria.

Numa segunda etapa, de junho 2004 a junho de 2005, as mentoras foram capacitadas no uso da informática e da internet. A partir de março de 2005 até a presente data (fevereiro de 2007), onze mentoras atuam com 29 professoras iniciantes. Usamos o feminino, mas há um professor no grupo das iniciantes.

As professoras iniciantes mantêm, numa plataforma específica para essa finalidade no Portal dos Professores, contatos semanais com suas mentoras por meio de correspondências eletrônicas. Nesses contatos, professoras iniciantes e mentoras desenvolvem um conjunto de experiências de ensino e aprendizagem (Mizukami et al., 2002). Essas experiências envolvem situações estruturadas que são planejadas conjuntamente por mentoras e professoras iniciantes, são desenvolvidas pelas professoras iniciantes em suas classes e estão voltadas para a minimização de dificuldades específicas indicadas pelas professoras iniciantes. As experiências de ensino e aprendizagem podem ser relacionadas às práticas pedagógicas em sala de aula, ao ensino de um conteúdo específico ou podem envolver atividades como a interação das professoras iniciantes com a comunidade dos pais dos seus alunos.

No caso das mentoras, são promovidas reuniões semanais com o grupo de pesquisadoras para discussão sobre 0 andamento dos diversos processos de mentoria que conduzem e de seu desenvolvimento profissional.

Nesse processo como um todo, adotamos uma metodologia de pesquisa-intervenção de natureza construtivo-colaborativa e as narrativas orais e escritas (correspondências e diários reflexivos) das professoras envolvidas (iniciantes e mentoras) têm sido a principal ferramenta de coleta de dados.

O Programa de Mentoria não foi concebido apenas como um processo de assistência tendo em vista necessidades de professores iniciantes. Seu desenvolvimento tem implicado na continuação dos processos de aprendizagem e desenvolvimento profissional por parte das mentoras, pois para a sua condução, é necessário o exame de crenças sobre o ensino e 0 aprender a ensinar; a construção de imagens de ensino coerentes com o que é preconizado como adequado; e o desenvolvimento de disposição para aprender a ensinar. Assim, o preparo das mentoras - um processo contínuo tem focalizado não somente o desenvolvimento de habilidades de relacionamento interpessoal e de reflexão, mas ainda o desenvolvimento de disposições e habilidades em ensinar e aprender a ensinar que são cruciais para o apoio a professores iniciantes (Wang; Odell, 2002).

Temos procurado favorecer o desenvolvimento das participantes, aliando o currículo 
flexível às possibilidades da interação via internet, desenvolvendo uma pedagogia centrada na resolução de problemas, considerada de modo expandido. Nesse processo, a prática reflexiva, seja individual ou coletiva, ocupa um lugar de destaque. Valorizamos os "processos de produção do saber docente a partir da prática [...]" e 0 ensino é "tomado como ponto de partida e de chegada [...]" (Pimenta, 2002, p. 22). Consideramos as possibilidades e os limites que os contextos escolares, sociais, econômicos, históricos e políticos impõem tanto às ações pedagógicas como à reflexão sobre elas por parte dos profissionais docentes, sejam elas as professoras em início de carreira ou as mentoras.

0 desenvolvimento de práticas reflexivas, via Programa de Mentoria, caracteriza- se por ser um processo de longa duração, que envolve a construção de uma base conceitual em termos teóricos e uma base de confiança em termos das relações entre as envolvidas, bases essas imprescindíveis para a continuidade e também para a investigação do programa proposto.

Destacamos, para esse texto, os resultados a seguir, por sua importância:

1. Mentoras e professoras iniciantes têm apresentado atitudes indicativas de valorização do próprio crescimento individual e intelectual e do crescimento individual e intelectual dos outros. 2. As participantes do Programa (pesquisadoras, mentoras e professoras iniciantes) têm mantido sistematicamente conversas interativas, via reuniões semanais e correspondências. Nessas conversas, estabelecem freqüentemente relações entre as idéias discutidas nos encontros entre mentoras e pesquisadoras, nos contatos das mentoras entre si ou delas com as professoras iniciantes. Tais relações também foram observadas em diferentes episódios que ocorrem no processo de mentoria quando, implícita ou explicitamente, convidam as outras participantes a concordar ou a oferecer explicações alternativas às conjecturas apresentadas.

3. A conversa interativa parece ter introduzido um elemento de inquirição no discurso do grupo, tendo em conta a maneira pelas quais as outras participantes são induzidas/convidadas a ir além da mera descrição de uma circunstância particular para relacionar o fato em pauta com outros exemplos, ou considerá-los sob outras perspectivas, ou à luz de idéias e princípios mais amplos, ou dos pressupostos em que se baseiam bem como de bases teóricas sobre o tema.

4. Observamos, em alguns casos, choques de paradigmas entre algumas díades (mentorasprofessora iniciante e mentoras- mentoras). Essa situação tem suscitado, às vezes, por parte das mentoras, a explicitação de sentimentos de desconforto e dificuldade em trabalhar com crenças diversas das suas.

5. As mentoras, aparentemente, têm vivenciado uma fase de desenvolvimento profissional com características muito semelhantes às das professoras que orientam, podendo ser classificadas como iniciantes em suas atividades formativas. Como tal, cada uma tem buscado apoio e incentivo com outras mentoras, especialistas e pesquisadoras.

6. Aos poucos, os quadros de referências das diversas participantes estão sendo delineados; processos de recolocação de idéias observados; e uma base de conversação colaborativa construída.

7. Observamos que paulatinamente 0 grupo de mentoras e pesquisadoras vem construindo uma comunidade de aprendizagem, pois evidenciamos movimentos na direção da definição de uma identidade grupal, com normas de interação estabelecidas. As diferenças pessoais têm sido respeitadas e há uma tendência das mentoras de responsabilizarem-se coletivamente tanto pela aprendizagem dos pares quanto das diferentes professoras iniciantes.

Um dos desafios da presente investigação tem sido a sistematização das conversas mantidas via correspondência entre mentoras e professoras iniciantes e aquelas realizadas durante as reuniões semanais envolvendo mentoras e pesquisadoras. Estamos trabalhando arduamente 
para estabelecer ferramentas para que os conhecimentos construídos, assim como os processos envolvidos, sejam identificados e compreendidos - especialmente os relacionados à construção de comunidades de aprendizagem de professores.

Um outro desafio corresponde à identificação e determinação da qualidade dos processos reflexivos relacionados à melhoria das práticas das mentoras e das professoras iniciantes.

0 modelo de acompanhamento das professoras iniciantes proposto no Programa de Mentoria e conduzido por professoras experientes tem se apresentado como uma importante ferramenta formativa, pois além de considerar as características dos processos de aprendizagem da docência indicados anteriormente, atenta para as especificidades das necessidades formativas de cada uma das professoras iniciantes.

0 fato de o Programa ser conduzido online exige uma nova ordem espaço-temporal para a realização das atividades formativas, tanto para as professoras iniciantes quanto para as mentoras. 0 uso da internet tem possivelmente favorecido os processos de aprendizagem profissional das iniciantes uma vez que não há um local e período predeterminados para ocorrerem. Cada uma acessa o Portal em locais e momentos variados, conforme disponibilidade.

As interações estabelecidas entre as díades - professoras iniciantes e mentoras têm permitido que as primeiras expressem com franqueza suas dificuldades, dilemas, dúvidas, o que possivelmente não ocorreria num contexto de formação que envolvesse outras pessoas e se desenvolvesse presencialmente.

As mentoras têm tido oportunidade de examinar criticamente sua atuação com as professoras iniciantes; desenvolver e implementar intervenções; e avaliá-las. As correspondências entre as mentoras e suas professoras iniciantes, entre elas e as pesquisadoras e os encontros presenciais entre essas últimas têm se configurado como contextos coletivos para o desenvolvimento profissional de todos - professoras iniciantes, mentoras e pesquisadoras -, pois têm possibilitado a construção de novos conhecimentos individuais e coletivos (Gallucci, 2003).

Apesar dos resultados ainda incipientes da pesquisa, os aspectos apontados revestem 0 Programa de Mentoria de um caráter diferenciado dos programas de formação continuada usualmente conduzidos em nosso contexto e apontam para a sua validade. A partir do diálogo construtivo mantido com o conjunto de professoras mentoras e iniciantes, estamos estabelecendo novas idéias e novas compreensões sobre o processo de aprender a ensinar e a ser professor em diferentes fases da carreira. Acreditamos que esses conhecimentos podem contribuir para informar políticas públicas que procurem reduzir o chamado choque de realidade que sofrem não poucos professores iniciantes e também para as que sejam dirigidas a professores em outras fases de desenvolvimento profissional ou para os formadores de professores.

0 desenvolvimento do Programa de Mentoria online tem se mostrado um processo desafiador e enriquecedor, que tem permitido a criação de vínculos profissionais fortes, a ampliação de conhecimentos e o domínio de tecnologias de educação a distância, com o é caso da internet, a aprendizagem e 0 desenvolvimento profissional da docência das participantes, mas é muito mais complexo do que se fosse presencial, porque exige uma logística nova.

Apesar da ausência de políticas públicas voltadas para os processos de indução de professores iniciantes, defendemos a possibilidade de atendimento a profissionais nessa fase da carreira, via internet, por meio de programas voltados para as suas necessidades formativas.

Entendemos ser possível a construção de comunidades de aprendizagem que apóiem os professores em suas práticas. Em nossa perspectiva, a formação continuaria centrada na escola, embora virtualmente, pois o seu foco seria 0 atendimento online das demandas de professores iniciantes, tendo em vista o contexto de atuação, tal como percebido e relatado por eles. Consideramos ser possível o estabelecimento de uma rede, de uma comunidade virtual de aprendizagem, 
que considere as características dos diferentes contextos de atuação a partir de programas de desenvolvimento profissional organizado sob essa perspectiva e que atenda cada professor iniciante individualmente. Nesse caso, os processos de criação, expansão, troca e desenvolvimento podem ocorrer sem prejuízos para os membros de tais comunidades, pois podem explicitar os contextos de atuação e realizar processos de troca e colaboração com os professores formadores.

Para concluir, destacamos mais uma vez que, no caso específico do Programa de Mentoria vinculado ao Portal dos Professores, temos considerado o contexto de atuação mediante as manifestações dos professores iniciantes por meio de correspondências encaminhadas às mentoras. Lembramos também que, para atender às necessidades formativas das professoras iniciantes, as professoras experientes - mentoras -, embora fossem professoras consideradas bem-sucedidas em suas carreiras profissionais, também participaram de processos de formação que consideraram a problemática do professor iniciante, sua necessidade de suporte educacional, a possibilidade de atendimento individualizado e em tempo adequado às suas necessidades, o contexto em que a atuação ocorre, entre outros temas.

Assim, no projeto de pesquisa que vimos desenvolvendo, temos realizado tanto a formação de professores iniciantes para se tornarem mais bem-sucedidos em seus contextos de atuação como a formação de formadores para atuar, por meio da internet, com professores iniciantes. Atuamos, portanto, nos dois pontos frágeis da formação profissional dos professores: o período de indução e a formação de formadores. Frágeis porque no mais das vezes, nos processos formativos de professores, não são atendidas as complexas especificidades das atuações docentes e suas necessidades formativas.

\section{Referências bibliográfic as}

ALMEIDA, M. E. B. Educação, ambientes virtuais e interatividade. In: SILVA, M. (Org.). Educação online: teorias, práticas, legislação, formação corporativa. São Paulo: Loyola, 2003. p. 202-215.

ARGYRIS, C.; SCHÖN, D. A. Organizational learning II: theory, method and practice. Reading (Ma): Addison-Wesley, 1996.

BALL, D. L. E.; COHEN, D. K. Developing practice, developing practitioners: toward a practice-based theory of professional education. In: DARLING-HAMMOND, L.; SYKES, G. (Eds.). Teaching as the learning profession: handbook of policy and practice. San Francisco: J ossey-Bass, p. 3-32, 1999.

BLIKSTEIN, P.; ZUFFO, M. K. As sereias do ensino eletrônico. In: SILVA, M. (Org.). Educação online: teorias, práticas, legislação, formação corporativa. São Paulo: Loyola, 2003. p. 23-38.

BORKO, H. Professional development and teacher learning: mapping the terrain. Educational Researcher, v. 33, n. 8, p. 3-15, 2004.

CALDERHEAD, J. Teachers: beliefs and knowledge structures and comprehension processes. In: CALDERHEAD, J .; CALFEE, R. C. (Ed.). Exploring teachers' thinking. New York: Macmillan, 1996. p. 709-725.

CLARK, C. et al. Continuing the dialogue on collaboration. American Educational Research J ournal, v.37, n.4, p.785-791, 1998. Collaboration as dialogue: teacher and researchers engaged in conversation and professional development. American Educational Research J ournal, v. 33, n. 1, p. 193-232, 1996.

COLE, A.; KNOWLES, J . G. Teacher development partnership research: a focus on methods and issues. American Educational Research Journal, v.30, n.3, p.473-495, 1993. 
DANI, L. S. C.; ISAÍA, S. M. de A. Ressignificando o fracasso escolar no ensino fundamental. In: 20 å Reunião Anual da ANPED. Anais... Caxambu, ANPED, 1997.

DARLING-HAMM OND, L. Review of Research in Education. American Educational Research Association, v. 20, 1994.

FERREIRA, L. A.; REALI, A. M. de M. R. Aprendendo a ensinar e a ser professor: contribuiç̄ões e desafios de um programa de iniciação à docência para professores de educação física. In: 28ª Reunião Anual da ANPED. Caxambu, ANPED, 2005. Anais... 2005.

GALLUCCI, C. Theorizing about responses to reform: the role of communities of practice in teacher learning. An occasional paper. University of Washington: Center for the Study of Teaching and Policy, 2003.

GROSSMAN, P.; WINEBBURG, S.; WOOLWORTH, S. Toward a theory of teacher community. Teachers College Record, v. 103, n. 6. p. $942-1012.2000$.

GROSSMAN, P.; THOMPSON, C.; VALENCIA, S. District policy and beginning teachers: where the twain shall meet. Research Report. Center for Study of Teaching and Policy, University of Washington, 2001.

HATTON, N.; SMITH, D. Reflection in teacher education: toward definition and implementation. Teaching and Teacher Education, v. 11, n. 1, p. 33-49, 1995.

KLEIN, R. Por uma educação de qualidade. Ensaio. Rio de Janeiro, v. 11, n. 38, p. 115-120, 2003.

KNOWLES, J. G.; COLE, A. L.; PRESSWORD, C. S. Through preservice teachers' eyes: exploring field experiences through narrative and inquiry. New York: Macmillan College Publishing Company, 1994.

MARCELO GARCIA, C. Pesquisa sobre a formação de professores. Revista Brasileira de Educação, n. 9, p. 51-75, 1998.

MCDIARMID, G. W. Realizing new learning for all students: a framework for the professional development of Kentucky teachers. National Center for Research on Teacher Learning, NCRTL, 1995.

MIZUKAMI, M. G. N. et al. Do projeto coletivo da escola a sala de aula: analisando processos de desenvolvimento profissional de professores das séries iniciais do ensino fundamental. São Carlos, DME/UFSCar, 2003. Relatório de pesquisa (FAPESP/Ensino Público). Não publicado.

Escola e aprendizagem da docência: processos de investigação e formação. São Carlos: EDUFSCar, 2002.

MORAN, J. M. Contribuições para uma pedagogia da educação online. In: SILVA, M. (Org.). Educação online: teorias, práticas, legislação, formação corporativa. São Paulo: Loyola, 2003. p. 39-73.

NOVA, C.; ALVES, L. Estação online: a "ciberescrita", as imagens e a EAD. In: SILVA, M. (Org.). Educação online: teorias, práticas, legislação, formação corporativa. São Paulo: Loyola, 2003. p. 105-124.

PACHECO, J . A.; FLORES, M. A. Formação e avaliação de professores. Porto: Porto Editora, 1999.

PICCOLLI, D. M.; OHNUMA, M. I. A. Relatório dos formadores: PROFA e PCN em Ação, 2002, mimeo.

PIMENTA, S. G. Professor reflexivo: construindo uma crítica. In: PIMENTA, S. G.; GHEDIN, E. (Orgs.). Professor reflexivo no Brasil: gênese e crítica de um conceito. São Paulo: Cortez, 2002. p. 17-52.

RAMAL, A. C. Educação com tecnologias digitais: uma revolução epistemológica em mãos do desenho instrucional. In: SILVA, M. (Org.). Educação online: teorias, práticas, legislação, formação corporativa. São Paulo: Loyola, 2003. p. 183-198.

RODGERS, C. Attending student voice: the impact of descriptive feedback on learning and teaching. Curriculum Inquiry, v. 36, n. 2, p. 209-237, 2006.

SANTOS, E. O. Articulação de saberes na EAD online: por uma rede interdisciplinar e interativa de conhecimentos em ambientes virtuais de aprendizagem. In: SILVA, M. (Org.). Educação online: teorias, práticas, legislação, formação corporativa. São Paulo: Loyola, 2003. p. 218-230. 
SCHOENFELD, A. H. Toward a theory of teaching-in-context. 1997. Disponivel em <http://www.gse.berkeley.edu/Faculty/ aschoenfeld/TeachInContext/teaching-in-context.html>. Acesso em 15 fev. 2000.

SCHÖN, D. Educating the reflective practioner. New York; J ossey-Bass: Teachers College Press, 1987.

SHULMAN, L. S. Knowledge and teaching: foundations of the new reform. Harvard Educational Review, v. 57, n. 1, p. 1-22, 1987.

SHULMAN, L. S. Those who understand: knowledge grow in teaching. Educational Researcher, v. 15, n. 2, p. 4-14, 1986.

TANCREDI, R. M. S. P.; REALI, A. M. M. R; MIZUKAMI, M. G. N. Programa de mentoria para professores das séries iniciais: implementando e avaliando um contínuo de aprendizagem docente. São Carlos, DME/UFSCar, 2005. Relatório de pesquisa, n. 1/ FAPESP/Ensino Público. Não publicado.

Van ZANTEN, A.; GROSPIRON, M. F. Les carrières enseignantes dans les établissements difficiles: fuite, adaptation et développement professionnel. VET Enjeux, n. 124, p. 224-268, 2001.

WANG, J ;; ODELL, S. J . Mentored learning to teach according to standards-based reform: a critical review. Review of Educational Research, v. 72, n. 3, p. 481-547, 2002.

WASSER, J. D.; BRESSLER, L. Working in the interpretative zone: conceptualizing collaboration in qualitative research teams. Educational Research, v. 25, n. 5, p. 5-15, 1996.

WEISS, E. M.; WEISS, S. G. Beginning teacher induction. ERIC Digest: ED436487, 1999.

Recebido em 08.02.07

Aprovado em 25.02.08

Aline Maria de Medeiros Rodrigues Reali é psicóloga, doutora em Psicologia Experimental, professora e orientadora no programa de Pós-Graduação em Educação da UFSCar.

Regina Maria Simões P. Tancredi é licenciada em matemática, doutora em Educação, professora e orientadora no Programa de Pós-Graduação em Educação da UFSCar.

Maria da Graça Nicoletti Mizukami é pedagoga, doutora em Ciências Humanas, pós-doutora em Formação de Professores pela Santa Clara University, professora e orientadora no Programa de Pós-Graduação em Educação da UFSCar e do Programa de Pós-Graduação em Educação, Arte e História da Cultura da Universidade Mackenzie. 